\title{
Primary Plasma Cell Leukemia Associated with Adult Fanconi Syndrome
}

\author{
Viviana Campisi, Claudio Tripodo, Carla Guarnotta, \\ Ada Maria Florena, Vito Franco
}

\section{Abstract}

Primary plasma cell leukemia (PCL) is a rare variant of multiple myeloma that occurs de novo in patients without a history of plasma cell disorder. We describe a case of $\lambda$ PCL that showed a prolonged survival of 2 years and 6 months associated with a generalized dysfunction of the proximal renal tubule. On presentation, the patient had anemia (hemoglobin level, $11 \mathrm{~g} / \mathrm{dL}$ ), thrombocytopenia (platelet count, 102,000/ $\mu \mathrm{L}$ ), and renal insufficiency (creatinine level, $2.75 \mathrm{mg} / \mathrm{dL}$; creatinine clearance, $19 \mathrm{~mL}$ per minute; urea, $71 \mathrm{mg} / \mathrm{dL}$ ). In addition to the common clinical picture, our case showed proteinuria $(30 \mathrm{mg} / \mathrm{dL})$, glycosuria $(150 \mathrm{mg} / \mathrm{dL})$ with normal glycemia, low uric acid concentration $(2.9 \mathrm{mg} / \mathrm{dL})$, and ion loss from the proximal renal tubule (P, $2.1 \mathrm{mg} / \mathrm{dL})$. These findings were compatible with the clinical picture of adult-acquired Fanconi syndrome, which can be observed in PCL/multiple myeloma but is almost exclusively associated with $\kappa$-chain restriction.

Clinical Leukemia, Vol. 1, №. 2, 130-132, 2006

Key words: Adhesion molecules, $\lambda$ light-chain disease, Multiple myeloma

\section{Introduction}

Plasma cell (PC) leukemia (PCL) is a rare PC disorder that can be considered the leukemic variant of multiple myeloma (MM). Two forms of PCL exist: the primary form occurs de novo in patients without a previous history of MM; the secondary form arises as a rare complication of late-stage disease in patients with MM. Criteria for the diagnosis of PCL have been defined by Kyle et al as an absolute PC count $>2000 / \mu \mathrm{L}$, with PCs comprising $>20 \%$ of peripheral blood cells. ${ }^{1-2}$ Primary PCL can be considered a distinct clinicopathologic entity, because clinical features, response to chemotherapy, and prognosis significantly differ from those of MM.

The clinicopathologic features resemble those of acute leukemia. Bones are less involved, but there is a higher incidence of organomegaly and tissue infiltration as well as diffuse marrow involvement and more pronounced cytopenias. Patients usually present with anemia and thrombocytopenia, and they have $>50 \%$ incidence of hepatosplenomegaly and lymphadenopathy (extramedullary involvement) as well as hypercalcemia and impaired renal function.

Commonly, patients with PCL are younger than those with MM. In contrast to MM, PCL has a more aggressive clinical course, the disease usually being progressive with a median survival of 6-8 months. In this report, we describe a case of light-chain restricted PCL $\lambda$, showing a prolonged survival of 2 years and 6 months and associated with adult Fanconi syndrome.

\section{Clinical Summary}

In November 2002, a 60-year-old woman was admitted to the Department of Oncohematology of our University Hospital complaining of asthenia and back pain. On presentation, she had anemia (hemoglobin level, $11 \mathrm{~g} / \mathrm{dL}$ ), thrombocytopenia (platelet count, 102,000/ $\mathrm{LL}$ ), and renal insufficiency (creatinine level, $2.75 \mathrm{mg} / \mathrm{dL}$; creatinine clearance, $19 \mathrm{~mL}$ per minute; urea, $71 \mathrm{mg} / \mathrm{dL}$ ). The white blood cell count was $14,400 / \mu \mathrm{L}$ with $23.6 \%$ of plasmacytoid lymphocytes on differential count

Dipartimento di Patologia Umana, Palermo, Italy

Submitted: January 1, 2006; Revised: June 1, 2006; Accepted: August 1, 2006

Address for correspondence: Viviana Campisi, MD, Dipartimento di Patologia Umana, Via del Vespro 129, Palermo, Italy Fax: 39-0916-553621; e-mail: vi_camp@yahoo.it

Electronic forwarding or copying is a violation of US and International Copyright Laws.

Authorization to photocopy items for internal or personal use, or the internal or personal use of specific clients, is granted by CIG Media Group, LP,

ISSN \#1931-6925, provided the appropriate fee is paid directly to Copyright Clearance Center, 222 Rosewood Drive, Danvers, MA 01923 USA 978-750-8400. 


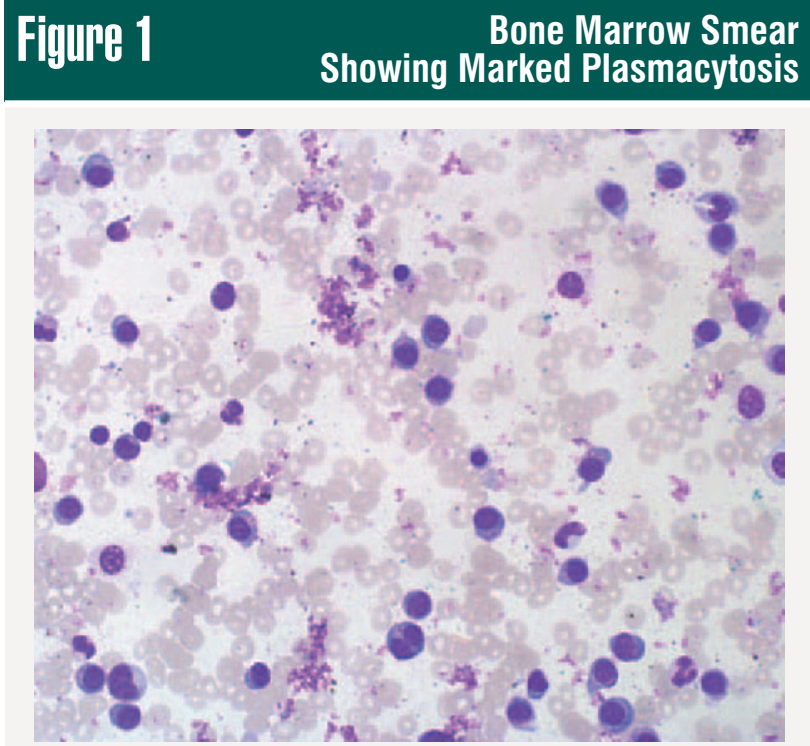

Original magnification $\times 400$.

$(3400 / \mu \mathrm{L})$. On bone marrow smear, marked plasmacytosis was evidenced, with PCs accounting for $57 \%$ of total cellularity (Figure 1).

Immunoelectrophoresis revealed a monoclonal $\lambda$ light-chain component at a concentration of $9.3 \mathrm{~g} / \mathrm{L}$. Immunoglobulin $\mathrm{G}$ (IgG) concentration was $5 \mathrm{~g} / \mathrm{L}$. These findings were consistent with the diagnosis of light-chain restricted PCL $\lambda$.

The serum lactate dehydrogenase value was $468 \mathrm{U} / \mathrm{L}$, and $\beta 2$ microglobulin was increased at $47 \mathrm{mg} / \mathrm{dL}$. The patient had proteinuria $(30 \mathrm{mg} / \mathrm{dL})$, glycosuria $(150 \mathrm{mg} / \mathrm{dL})$, fasting glucose concentration $(80 \mathrm{mg} / \mathrm{dL})$, hypokalemia $(\mathrm{K}, 2.9 \mathrm{mEq} / \mathrm{L})$, hypophosphatemia (P, $2.1 \mathrm{mg} / \mathrm{dL})$, and low uric acid concentration $(2.9 \mathrm{mg} / \mathrm{dL})$.

Neither evidence of bone lesions nor extramedullary involvement (hepatomegaly, splenomegaly, or lymphadenopathy) was found. In December 2002, treatment with multiagent chemotherapy, a combination of vincristine/doxorubicin/dexamethasone (VAD), was started. After 3 cycles, the patient exhibited a partial response ( $\lambda$ light-chain component, $1853 \mathrm{~g} / \mathrm{L}$; IgG, $2693 \mathrm{~g} / \mathrm{L}$ ), defined as a decrease of $>50 \%$ in serum or $75 \%$ in urine of the monoclonal protein associated with the disappearance of circulating PCs. In March 2003, she received 1 more cycle of VAD.

One month later, as a result of disease progression (creatinine level, $2.3 \mathrm{mg} / \mathrm{dL} ; \beta_{2}$-microglobulin, $26 \mathrm{mg} / \mathrm{dL}$ ), therapy with VMCP (vincristine/melphalan/cyclophosphamide/prednisolone) was started. After 2 cycles, the response was unsatisfactory (IgG, $3592 \mathrm{~g} / \mathrm{L} ; \lambda$ light chain, $3199 \mathrm{~g} / \mathrm{L}$; creatinine level, $2.75 \mathrm{mg} / \mathrm{dL}$; $\beta_{2}$-microglobulin, $17.5 \mathrm{mg} / \mathrm{dL}$ ), and this regimen was switched to vincristine/cyclophosphamide/dexamethasone. After 2 cycles of this new regimen, the patient presented severe neutropenia, and although the third cycle was deferred (after 29 days), she turned leukopenic (leukocyte count, 2500/mL). Therefore, the third and fourth cycles were administered at lower dosages.

In October 2003, the patient underwent a bone marrow biopsy, which showed slightly hypercellular bone marrow, with interstitial, intrasinusoidal, and perisinusoidal infiltration by neoplastic PCs (Figure 2) displaying the following phenotypic profile:

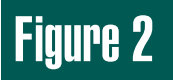

Bone Marrow Biopsy Showing Interstitial, Intrasinusoidal, and Perisinusoidal Infiltration by Neoplastic Plasma Cells

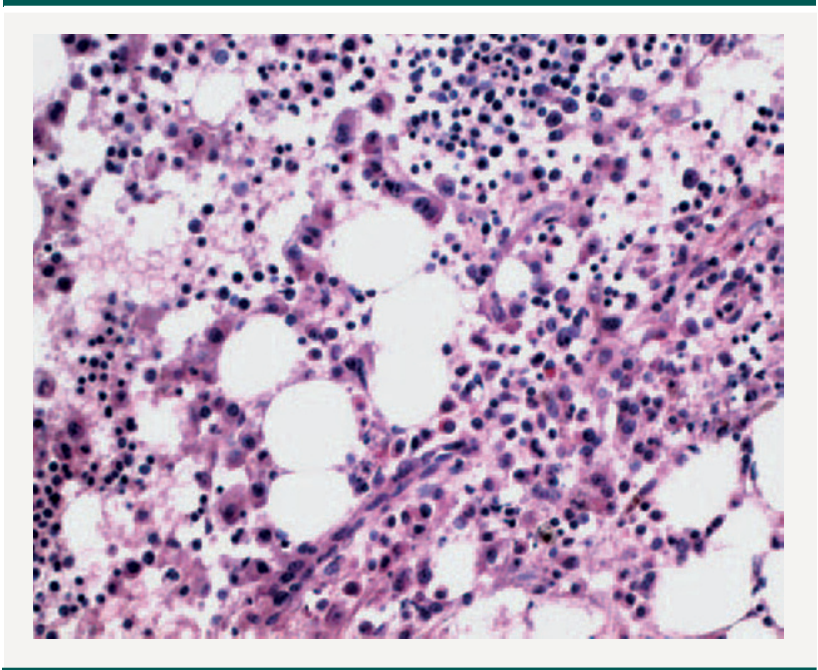

Original magnification $\times 250$.
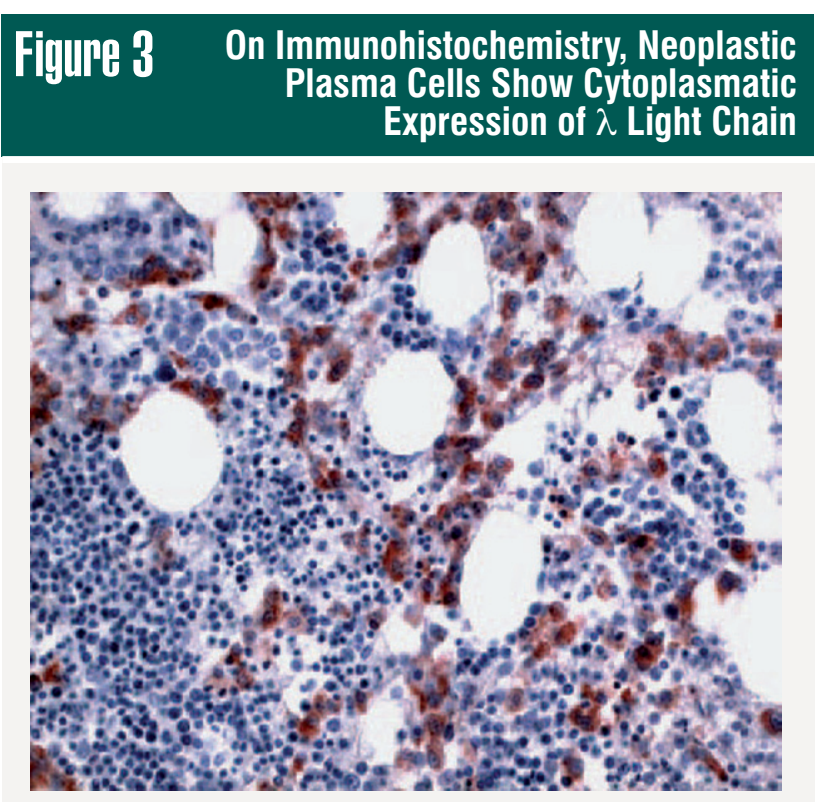

Anti- $\lambda$ light-chain monoclonal antibody (original magnification $\times 250$ ).

$\mathrm{CD} 44^{+}, \lambda$-positive, CD138 ${ }^{+}$, epithelial membrane antigen-positive, $\mathrm{CD} 162^{+}$, $\mathrm{\kappa}$-negative, $\mathrm{CD} 56^{-}$, CD20-, and leukocyte common antigen-negative. On re-evaluation, disease progression was recorded, and therefore thalidomide was started.

In January 2004, another re-evaluation of the disease was performed, and 5 cycles of vincristine/dexamethasone were administered.

In May 2004, the patient was readmitted to our hospital presenting severe renal insufficiency (creatinine level, $3.6 \mathrm{mg} / \mathrm{dL}$; creatinine clearance, $12 \mathrm{~mL}$ per minute). Thalidomide was administered as a salvage procedure, but because of severe neurotoxicity, the treatment was subsequently stopped. The patient developed progressive, unresponsive disease and died in May 2005, 2 years and 6 months after presentation. 


\begin{tabular}{|c|c|c|c|c|c|c|c|}
\hline \multirow{3}{*}{ Study } & \multirow{3}{*}{$\begin{array}{c}\text { Number } \\
\text { of } \\
\text { Cases }\end{array}$} & & & \multicolumn{4}{|c|}{$\begin{array}{r}\text { Occurrence of Renal Failure in the Major Series of Primary } \\
\text { Plasma Cell Leukemia Reported in the Literature2-5 }\end{array}$} \\
\hline & & \multicolumn{2}{|c|}{ Light Chain } & \multirow{2}{*}{$\begin{array}{c}\text { Renal } \\
\text { Failure } \\
(\%)\end{array}$} & \multirow{2}{*}{ Treatment } & \multirow{2}{*}{$\begin{array}{l}\text { Response } \\
\text { (\%) }\end{array}$} & \multirow{2}{*}{$\begin{array}{l}\text { Median } \\
\text { Survival } \\
\text { (Months) }\end{array}$} \\
\hline & & $\lambda(\%)$ & $\kappa(\%)$ & & & & \\
\hline Costello et al2 & 18 & 20 & 80 & 56 & $\begin{array}{l}\text { VAD; C2H2OP; Cyclophosphamide/Methylprednisolone; } \\
\text { VMCP; MP; high-dose Melphalan; Dexamethasone }\end{array}$ & $\begin{array}{l}\text { CR: } 5.6 \\
\text { PR: } 61 \\
\text { F: } 33.4\end{array}$ & 7 \\
\hline Garcìa-Sanz et al ${ }^{3}$ & 26 & - & - & 44 & Melphalan/Prednisone; VMCP/VBAP & $\begin{array}{l}\text { CR: } 29 \\
\text { PR: } 8 \\
\text { F: } 63\end{array}$ & 8 \\
\hline Vela-0jeda et al ${ }^{4}$ & 24 & - & - & 50 & VAD; VMCPA; M-80 & $\begin{array}{l}\text { CR: } 12 \\
\text { PR: } 17 \\
\text { F: } 71\end{array}$ & 13.8 \\
\hline Jiménez-Zepeda et al ${ }^{5}$ & 8 & 87.5 & 12.5 & 60 & $\begin{array}{l}\text { VAD; Melphalan/Dexamethasone; MP; } \\
\text { Cyclophosphamide/Dexamethasone/Thalidomide }\end{array}$ & $\begin{array}{l}\text { PR: } 50 \\
\text { F: } 50\end{array}$ & 6.75 \\
\hline
\end{tabular}

Abbreviations: $\mathrm{C} 2 \mathrm{H} 2 \mathrm{OP}=$ vincristine/doxorubicin/cyclophosphamide/prednisone; $\mathrm{F}=$ treatment failure; $\mathrm{M}-80=\mathrm{melphalan} 80 \mathrm{mg} / \mathrm{m}^{2}$ plus dexamethasone $40 \mathrm{mg} / \mathrm{m}^{2}$; $\mathrm{MP}=$ melphalan/prednisone; VBAP = vincristine/bleomycin/doxorubicin/prednisone; VMCPA = vincristine/melphalan/cyclophosphamide/prednisone/doxorubicin

\section{Discussion}

Renal failure has been reported to be a rather frequent adverse factor contributing to poor overall survival of patients with primary PCL. The occurrence of renal failure in the major reported series of primary PCL is summarized in Table $1.2-5$

Plasma cell dyscrasia secreting free light chain, exclusively of $\kappa$ isotype, can be complicated by Fanconi syndrome. Fanconi syndrome is a generalized dysfunction of the proximal renal tubule characterized by glycosuria with normal glycemia, aminoaciduria, phosphaturia, uricosuria, and bicarbonaturia.

In addition to the common clinical picture, our case showed proteinuria $(30 \mathrm{mg} / \mathrm{dL})$, glycosuria $(150 \mathrm{mg} / \mathrm{dL})$ with normal glycemia, low uric acid concentration $(2.9 \mathrm{mg} / \mathrm{dL})$, and ion loss from the proximal renal tubule $(\mathrm{P}, 2.1 \mathrm{mg} / \mathrm{dL})$. These findings were compatible with the clinical picture of adult acquired Fanconi syndrome.

In this disease, the dysfunction of the proximal renal tubule is more likely related to $\kappa$ light chains than to $\lambda$ light chains. Fanconi syndrome is associated with specific properties of the $\mathrm{V}$ domain of the $\kappa$ light chain. It has been demonstrated that $\kappa$ variable domains are more resistant to protease degradation and have a self-reactivity to form crystals. A possible mechanism that explains the dysfunction of the proximal renal tubule is that light chains in these patients cannot undergo complete proteolysis, thus accumulating in lysosomal compartments and forming crystal structures in the tubular epithelial cells. ${ }^{6}$

The case we reported showed $\lambda$ light-chain restriction. The association of Fanconi syndrome with $\lambda$ light-chain proteinuria is rare and could reflect the different physicochemical properties of the light-chain subtypes, specifically their solubility and polymerization potential.

On immunohistochemistry, malignant PCs expressed CD38, cytoplasmatic $\lambda$ light chains, CD44 (hyaluronic acid cell adhesion molecule), CD138 (syndecan-1), CD162 (P-selectin glycoprotein ligand1 ), and epithelial membrane antigen, and were negative for leukocyte common antigen, CD20, CD56, and $\kappa$ light chains (Figure 3).
CD38 and CD138 are immunophenotypical markers of PCL. CD44 is a homing receptor that plays an important role in leukocyte rolling and lymphocyte migration, and it is generally expressed in circulating lymphomas migrating in the bone marrow. In PCL, malignant PCs do not express CD56 antigen, which is commonly found in myeloma cells. ${ }^{7} \mathrm{CD} 56$ is an adhesion molecule that plays a key role in anchoring PCs to the bone marrow stroma. The lack of CD56 is a hallmark of PCL, and it is strictly related to the trend of malignant PCs to circulate in the peripheral blood and to a lower osteolytic potential.

In addition to this molecule-adhesion profile, we also reported the expression of CD162, the major ligand of P-selectin, which has recently been described as being a marker of PC differentiation.

\section{Conclusion}

Response to treatment of PCL is poor. Patients treated with standard melphalan and prednisone have a median survival of 2 months. Those treated with VAD or other aggressive regimens show an improved median survival of 20 months. ${ }^{8}$ In younger patients, high-dose chemotherapy with autologous bone marrow or peripheral stem cell transplantation should be considered.

\section{References}

1. Kyle RA, Maldonado JE, Bayrd ED. Plasma cell leukaemia: report of 17 cases. Arch Intern Med 1974; 113:813-818.

2. Costello R, Sainty D, Bouabdallah R, et al. Plasma cell leukaemia: a report of 18 cases. Leuk Res 2001; 23:103-107.

3. García-Sanz R, Orfao A, Gonzalez M, et al. Primary plasma cell leukemia: clinical, immunophenotypic, DNA ploidy, and cytogenetic characteristics. Blood 1999; 93:1032-1037.

4. Vela-Ojeda J, Garcia-Ruiz Esparza MA, Rosas-Cabral A, et al. Intermediate doses of melphalan and dexamethasone are better than vincristine, adriamycin, and dexamethasone (VAD) and polychemotherapy for the treatment of primary plasma cell leukemia. Ann Hematol 2002; 81:362-367.

5. Jiménez-Zepeda VH, Dominguez-Martinez VJ. Vincristine, doxorubicin, and dexamethasone or thalidomide plus dexamethasone for newly diagnosed patients with multiple myeloma? Eur J Haematol 2006 [Epub ahead of print].

6. Ma CX, Lacy MQ, Rompala JF, et al. Acquired Fanconi syndrome is an indolent disorder in the absence of overt multiple myeloma. Blood 2004; 104:40-42.

7. Saccaro S, Fonseca R, Veillon DM, et al. Primary plasma cell leukemia: report of 17 new cases treated with autologous or stem-cell transplantation and review of the literature. Am J Hematol 2005; 78:288-294.

8. Wohrer S, Ackermann J, Baldia C, et al. Effective treatment of primary plasma cell leukemia with thalidomide and dexamethasone--a case report. Hematol J 2004; 5:361-363. 